\title{
Hotterdam: Mapping the social, morphological, and land-use dimensions of the Rotterdam urban heat island
}

Climate scientists forecast that heat waves will occur more often in the Netherlands in the coming decades. The Hotterdam study accordingly measured urban heat and modelled the surface energy balance in the Dutch city of Rotterdam. It identified in detail the city's social, morphological, and land-use dimensions using a geographic information system (GIS), 3D models, and satellite images. It used hierarchical and multivariate regression analyses to determine the links between temperatures and the surface energy balance on the one hand, and social, morphological, and land-use aspects on the other. The Hotterdam study did establish a link between the urban heat island effect in Rotterdam and the health of its population. It also statistically explained the high rate of mortality among seniors seventy-five and over during the summer of 2006. The spatial concentration of senior citizens, the average age of the buildings they live in, and the sum of the sensible heat flux and storage heat flux play a large role. Imperviousness, the leaf area index, the building envelope, surface water, and shade are the dimensions that best explained the Rotterdam urban heat island. We mapped these aspects in two heat-maps that help in setting priorities for implementing climate adaptation measures.

Keywords: urban heat island, morphology, land use, elderly, climate adaptation, Rotterdam 


\section{Introduction}

\subsection{Context}

The European heat wave of 2003 was something of a wake-up call. The heat struck France particularly hard that August. In a matter of two weeks, the national health system collapsed, and over fourteen thousand citizens were dead. The city of Paris felt the impact of an estimated five thousand heat-related deaths, predominantly among its senior citizens. The research on cities like Paris and London that followed in the years after underscored that "urban heat islands have significant implications for the comfort, energy and health of citizens" (Mavrogianni et al., 2011). The case study of Paris provided valuable insights into the way public health, social factors, housing conditions, environmental factors, and urban heat islands aggravate mortality during a severe heatwave (Vandentorren et al., 2006). The University College London (UCL) Lancet Commission identified urban heat islands as one of the leading challenges in shaping cities for health. The Lancet Commission stated in this context that cities are complex systems in which morphology, land use, and spatial location play key roles (Rydin et al., 2012).

As result of the urban heat island effect, a city may be warmer at times than its surrounding area, especially at night. In the winter this will result in a positive effect. The city will be less cold, so temperatures will be less extreme. In the summer, however, a heat island will aggravate the health of citizens, especially seniors. In this context it is important to emphasize that both heatwaves and urban heat islands are constrained to specific areas; they are regional occurrences that impact local areas. While the 2003 heatwave had a devastating impact on French cities, the Dutch cities of Amsterdam, Rotterdam, and The Hague avoided this natural disaster. Statistical data do not show much of an increase in mortality in these cities, which is in sharp contrast to the heatwave that hit the same region in 2006. July 2006 became the warmest month on record for the Netherlands, resulting in one thousand deaths. Because heatwave events are regional and cities are complex local urban systems, research into the effect of urban heat islands usually explores one city at a time and could best be classified as a collection of case studies. The Hotterdam research project is a case study of the urban heat island effect in the Dutch city of Rotterdam with a distinct focus on the city's social, morphological, and land-use aspects that contribute to the urban heat island effect as evidenced by the excess mortality of elderly citizens during heatwaves.

\subsection{Relevance and urgency}

The Hotterdam study is relevant and urgent because of three parallel developments: a changing climate, an ageing popula- tion, and enduring urban growth in the Randstad Holland conurbation. These three developments are expected to increase the potential impact of the urban heat island effect on respective societies.

In 2014 the Royal Netherlands Meteorological Institute (Dutch Koninklijk Nederlands Meteorologisch Instituut, KNMI) published four new scenarios on how the climate in the Netherlands might develop in the future: KNMI'14. These scenarios include predictions for 2050 and 2085. On their basis, the KNMI predicts that the number of hot summer days will increase, as will the likelihood of heatwaves. Air quality is forecasted to deteriorate during warm summers, and long periods of drought may occur. The rise in temperature will lead to more deaths during the summers. Hot and problematic summers will become more frequent than currently (KNMI, 2014).

Statistics Netherlands (Dutch Centraal Bureau voor de Statistiek, CBS) issued a forecast on the development of the Dutch population between 2014 and 2060 (van Duin \& Stoeldraijer, 2014). By 2040 the number of seniors sixty-five and above will quickly rise from 2.9 million to 4.8 million. After that their share will stabilize at just over a quarter of the population. According to the Netherlands Environmental Assessment Agency (Dutch Planbureau voor de Leefomgeving, PBL) and the Netherlands Bureau for Economic Policy Analysis (Dutch Central Planning Bureau, $C P B$ ), the percentage of seniors seventy-five and above will rise even more strongly (de Jong \& Daalhuizen, 2014). In 2012, 7.1\% of the population was seventy-five or older. By 2040 this share in the overall population will have grown to $14.5 \%$. Those that are most vulnerable to urban heat will double in the next decades. There is sufficient evidence to attribute the excess mortality of seniors to urban heat islands (Vandentorren et al., 2006; Heaviside et al., 2016).

The overall population in Randstad Holland will continue to grow as well. The CBS and PBL (2011) forecast an increase of 700,000 inhabitants by 2025 and another 400,000 between 2025 and 2040. The cities in Randstad Holland are likely to become less green and more impervious, potentially resulting in increased (atmospheric and surface) urban heat islands in cities such as Amsterdam, Rotterdam, and The Hague.

\subsection{Atmospheric and surface urban heat islands}

The atmospheric urban heat island refers in this context to the air temperature differences between cities and their surrounding (green) areas. Such differences can reach up to $10^{\circ} \mathrm{C}$ and occur especially after sunset. In the daytime these temperature differences are often smaller. During the day the city accumulates heat in buildings, pavements, surface water, and the 
ground. After sunset the urban area releases this heat slowly because of the heat capacity and thermal conductivity of the construction materials used in the built environment, predominantly concrete and asphalt. The natural cooling effect of vegetation is lacking in cities because pavement and buildings have replaced much of the original green areas.

The surface urban heat island refers to the temperature differences between parts of the city's surface (and not air): between asphalt roofing and treetops, and between pavement and surface water. These temperature differences are often more substantial and occur during the daytime. In the daytime, the atmospheric heat island and the surface heat island display vastly different spatial patterns. In the night, their spatial patterns align when the city's surface is the only remaining source of heat. Data on the surface heat island can be used to understand the energy processes that take place in urban areas, also known as the surface energy balance (Harman, 2003).

\subsection{Research questions}

The Hotterdam research project looked into the urban heat island effect in the city of Rotterdam from the perspective of climate adaptation. What insights could support altering the behaviour of residents, improving buildings, and making changes in the built environment? The Municipality of Rotterdam commissioned the research. It asked for insights into the extent of the urban heat island effect in Rotterdam, the impact on its citizens, and the role that morphology, land use, and spatial location play. The project addressed four specific research questions:

- Does the urban heat island effect impact all parts of the city of Rotterdam equally, or are distinct districts more affected than others; if so, which areas are these?

- Does a link exist between the urban heat island in the city of Rotterdam and the mortality rate among senior citizens during heatwaves?

- Can the differences in the urban heat island effect between districts be explained by the morphology and land use of the city of Rotterdam?

- Do the social, morphological, and land-use dimensions of the urban heat island effect result in coherent spatial patterns that allow an area-oriented approach in the urban planning and management of the city?

\section{Research design}

The research design of the Hotterdam study included three main steps. The first step was collecting data on the urban heat island in the city of Rotterdam, social data on its citi- zens and housing, and data on the morphology and land use of Rotterdam. The second step involved processing the data and mapping it in ArcGIS, using a fixed grid. The third step was analysing the links between urban heat, excess mortality, morphology, and land use by conducting multivariate regression analyses on the underlying numeric data per grid cell. The outcome of the regression analyses was used to perform cluster analyses, resulting in so-called social and spatial heat maps. We explain the three steps below in more detail.

\subsection{Data collection}

The project acquired data sets that helped describe the range and severity of the urban heat island, the vulnerable segment of the Rotterdam population (including factors that puts it additionally at risk), and the city's morphology and land use.

A (historical) data set that describes the weather in the various neighbourhoods of the city of Rotterdam does not exist. The KNMI does take measurements at Rotterdam The Hague Airport; however, at a requisite distance from built-up areas. Although their dataset is not sufficient to describe the temperature differences within the city, it was used to identify the critical heatwave event that had a measurable impact on the health of the elderly citizens living in Rotterdam in July 2006.

To overcome the lack of fine temperature measurements, several researchers in this field use remote sensing or crowdsensing to more accurately map the urban heat island. Dousset and Gourmelon (2003) pioneered the use of satellite imagery for visualising urban heat islands. They documented the Paris urban heat island during the heatwave of August 2003 and checked this data against the excess mortality that resulted from the meteorological disaster (Dousset \& Gourmelon, 2003; Dousset et al., 2011). Chapman et al. (2017) recently applied crowdsensing in the case of the London urban heat island using Internet-of-Things devices owned by the public: Netatmo urban weather stations. The Hotterdam project had us obtain Landsat 5 and Landsat 8 satellite imagery from USGS's EarthExplorer repository and pre-process the images by geo-rectifying and atmospherically correcting them. Landsat images are available as open access downloads, much like the satellite images from the European Space Agency.

Next, we measured the outdoor air and indoor air temperature, using a citizen science approach. We recorded the temperature in one thousand Rotterdam homes and at three hundred public spaces in the summer of 2014 (van der Hoeven et al., 2014). The temperatures were taken using low-cost sensors commonly used in the transport sector: the PakSense UltraContact temperature monitoring label. The typical temperature accuracy 


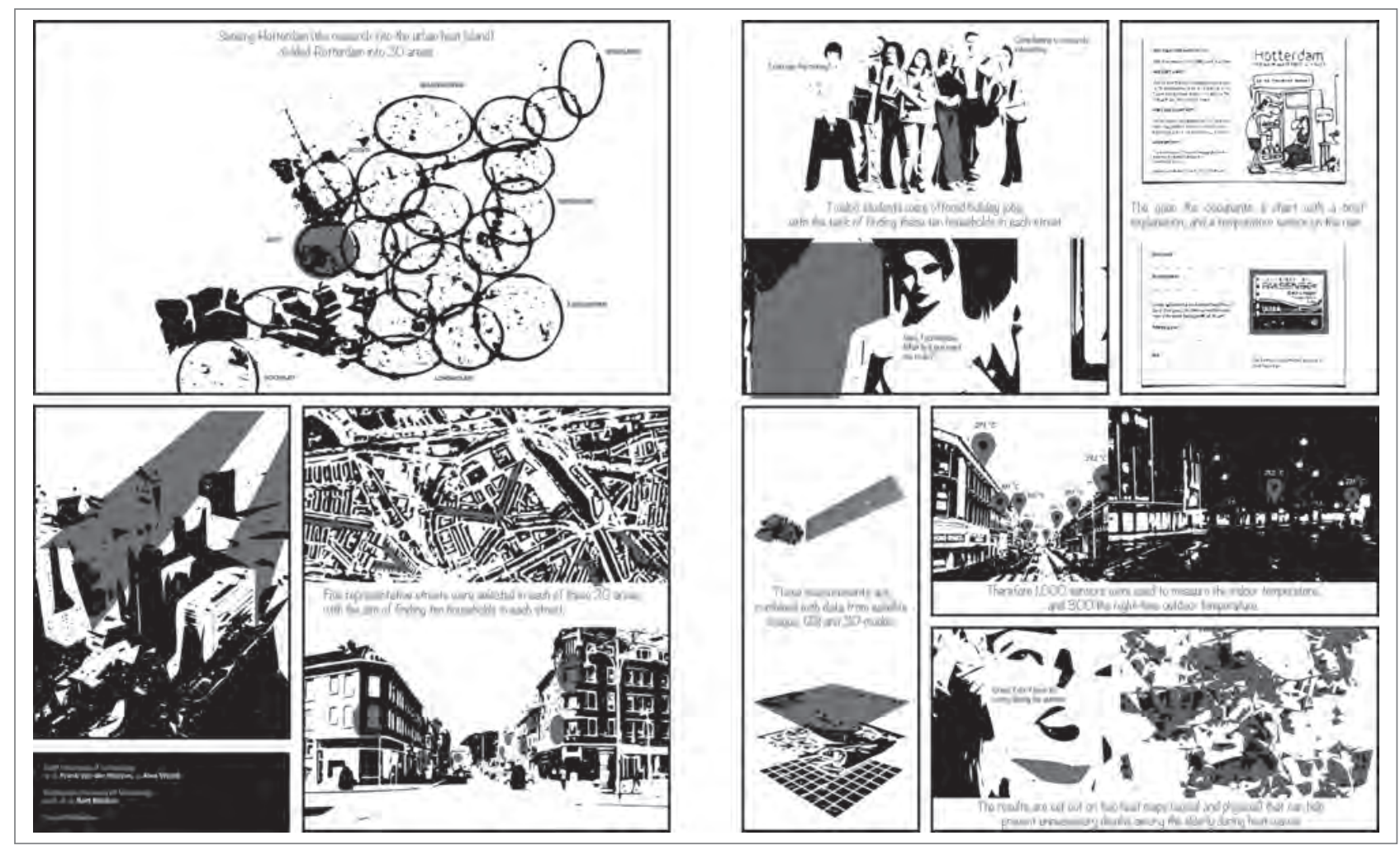

Figure 1: Sensing Hotterdam: storyboard that outlines the crowd-sensing (author: Frank van der Hoeven).

of these sensors is $\pm 0.5^{\circ} \mathrm{C}$, when operating between $-10{ }^{\circ} \mathrm{C}$ and $30^{\circ} \mathrm{C}$. Ten students were assigned to find a hundred participants each. Each student visited five selected streets in two selected neighbourhoods. Going from door to door, they were assigned to find ten participants on each street. The students briefly explained the aims of the research to the resident and handed out simple instructions together with the sensor. The residents were asked to place the sensors in their living rooms, out of the sunlight and away from heat sources such as televisions or computers. Two months after they distributed the temperature sensors the students collected them by revisiting the participating citizens. If the citizens were not at home, students visited them a second time. If they were still not at home, the students left an envelope behind that the residents could use to return the sensor. The sensors took readings from the end of July until mid-September 2014.

During the same period we measured the outdoor temperature with the same type of sensors. The authors placed three sensors on each of the one hundred streets, using a total of three hundred sensors. A small magnet was attached to the sensor. Using this magnet we attached the sensors to street and traffic signs two metres above ground level, on one side of the street in a row. The sensors measured the outdoor temperature on the same streets where residents had been approached to take the indoor temperature readings. This made it possible to compare the measurements.
The data specialists of the Municipality of Rotterdam acted as brokers between the authors and various agencies and provided us with data from several sources:

- Population data from the Rotterdam municipal personal data records;

- Land use from the Rotterdam GIS system;

- The population data from Statistics Netherlands;

- The Current Dutch Elevation Map (AHN);

- The Basic Registration of Addresses and Buildings (BAG) from the cadastre;

- The topographical map of the Netherlands (TOP10NL) from the cadastre; and

- Energy labels for buildings from Bespaar Lokaal.

\subsection{Processing and mapping}

We built a geodatabase in ArcGIS in which we collected all relevant information. For each hectare in Rotterdam, for each grid cell of $100 \times 100 \mathrm{~m}$, we generated numeric data to be used in the third step of the methodology: the multivariate regression and cluster analyses. The grid we applied is the smallest spatial unit for demographic data used by Statistics Netherlands (CBS). It also resembles the resolution of the infrared data in Landsat satellite images $(120 \times 120 \mathrm{~m})$. A smaller grain size would not have produced more accurate results. 

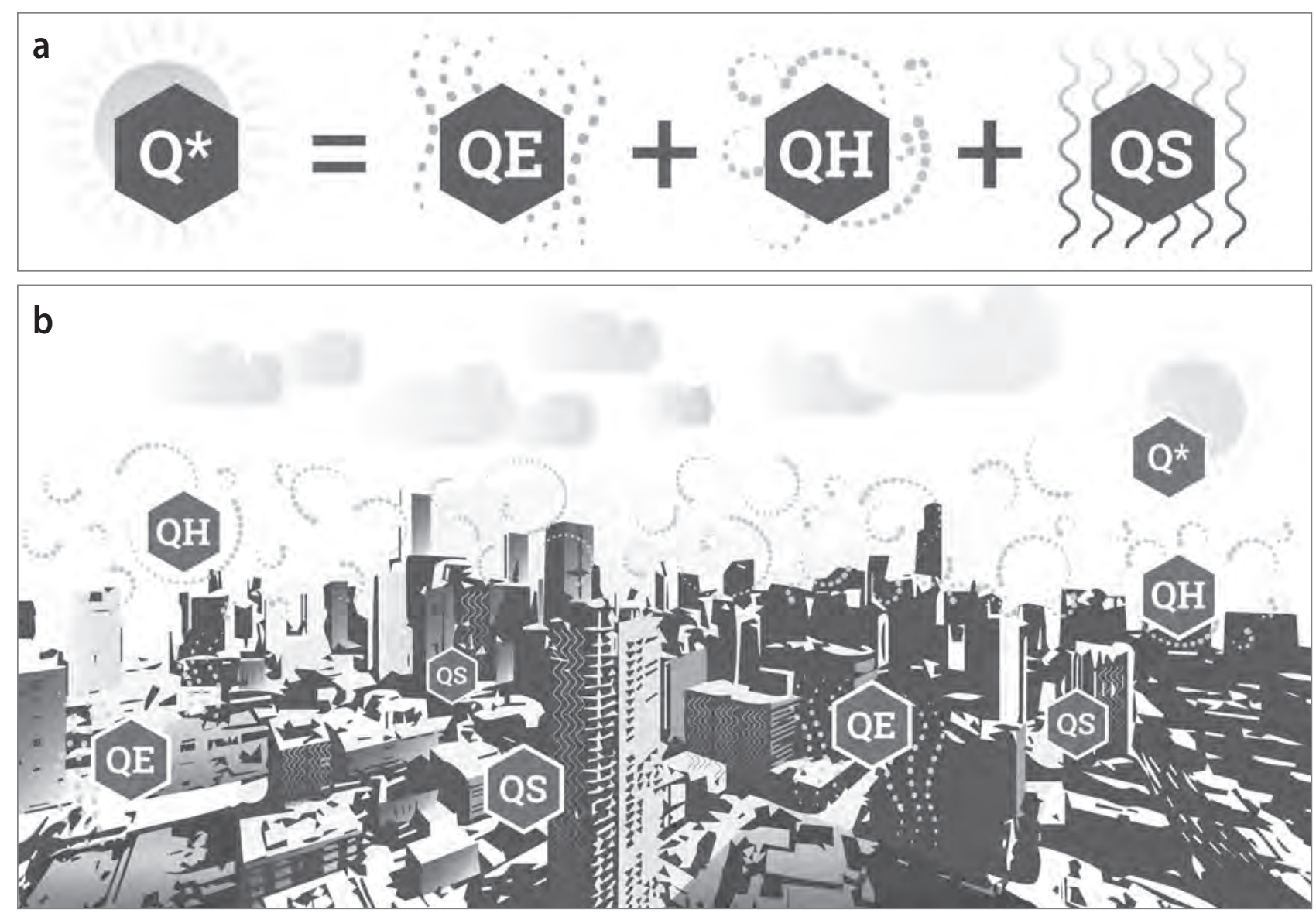

Figure 2: The surface energy balance in formula (a) and graphic (b) (author: Frank van der Hoeven).

Note: $\mathrm{Q}^{*}=$ net solar radiation received by the earth's surface, $\mathrm{QE}=$ energy consumed through evaporation (by water and greenery), $\mathrm{QH}=$ sensible heat (conversion of heat from surface to air), QS = energy absorbed by the ground, buildings, and surface water.

In the case of Hotterdam, we included in our research design the use of geo-located health data, which was provided by the municipal statistical office. Using health data is often complicated because of privacy concerns. Adhering to the grid size of $100 \times 100 \mathrm{~m}$ allowed us to work at a high spatial resolution while it was not necessary to receive or display private data on individual citizens. By removing citizens' personal information, we were able to store the datasets as open data. In the end we displayed the data as a categorized set of maps: the so-called Atlas, which again used a resolution of $100 \times 100 \mathrm{~m}$.

\subsubsection{Heat}

With the help of the KNMI dataset, we made an overview of the average maximum temperatures in June, July, and $\mathrm{Au}$ gust 2000 up to 2013. These were checked against the number of deaths in Rotterdam among seniors seventy-five and over (data provided by the CBS) to identify critical heatwave events.

In the middle of September 2014, we recollected eight hundred out of the one thousand temperature sensors from resi- dents. Two hundred participants were not at home when we revisited or did not respond to our requests to send the sensors back. We recollected two hundred out of three hundred sensors placed in public spaces. The other one hundred sensors had disappeared. We did, however, anticipate such a loss by putting three sensors on each street. In the end we had covered almost every street with at least one sensor. The data from the sensors were manually retrieved and entered into the ArcGIS database.

We used remote sensing to determine the city's surface temperature. We obtained a Landsat 5 image that NASA took during the extreme heat wave event in 2006. The image was taken on 16 July that year and portrays the city of Rotterdam after an extensive accumulation of heat in the ground, surface water, pavements, and buildings. The infrared band of the Landsat 5 image (Band 6) was used to determine land surface temperature. We atmospherically corrected the band with the use of NASA's online Atmospheric Correction Parameter Calculator (Barsi et al., 2005). This was translated into a land surface temperature image (Yale Center for Earth Observation, 2010) using an open source application developed by the European Space Agency: BEAM-VISAT (currently replaced 
by SNAP). We included the surface temperature map in the ArcGIS database.

The same Landsat 5 image was used to model the surface energy balance. An application called ATCOR2 was used to determine the surface energy balance. ATCOR2 (originally developed at the German Aerospace Centre) produces images of the net radiation, the sensible heat flux, the latent heat flux, and the storage heat flux. Net radiation is the absorbed shortwave solar radiation plus the longwave radiation that is emitted from the atmosphere minus the longwave radiation that is emitted from the surface. Sensible heat flux is the radiation that heats up the air. Latent heat flux is the energy that facilitates evapotranspiration from plants and evaporation from surface water. Storage heat flux is the radiation that warms up buildings, surface water, and the ground. We included the net radiation, sensible heat flux, latent heat flux, and storage heat flux maps in the ArcGIS database.

\subsubsection{Socio-spatial dimensions}

Mortality among seniors, especially those over seventy-five, increases during heatwaves. The spatial distribution of seniors and the urban conditions that influence their mortality vary throughout the city. We again used the hectare grid to create maps on:

- The concentrations of citizens seventy-five years old living in Rotterdam;

- The number of deaths that occurred in July 2006 in the age group $75+$;

- The number of deaths that occurred on average in the age group 75+ in July over the period 2000-2013;

- The difference between the number of deaths per hectare that occurred in July 2006 and the average number of deaths per hectare that occurred in July from 2000 to 2013 , resulting in the 2006 excess mortality per hectare due to (urban) heat.

The age of homes and the level of their insulation determine in part the likelihood of seniors dying prematurely (Vandentorren et al., 2006). Considering that homes act as filters between senior citizens and ambient outdoor temperatures, we used two datasets that could function as a possible indicator of the (energy) quality of such buildings: energy labels and building age. We calculated averages for each hectare.

\subsubsection{Spatial dimensions}

We based the maps on morphology and land use on three types of data: data derived from a 3D model of the city of Rotterdam, satellite imagery, and data that we obtained from the municipal GIS system.
Imperviousness, the leading cause of the urban heat island, was determined through a particular procedure to treat satellite imagery: spectral unmixing. The satellite images used in the case of the Rotterdam analysis were a Landsat 5 image (TM) that NASA took on 16 July 2006 and a Landsat 8 image (OLI) taken on 22 July 2014. Surface albedo, the normalized difference vegetation index (NDVI), and the leaf area index (LAI) were produced using ATCOR2. Both the NDVI and the LAI are by-products of this software's atmospheric correction procedure. The TOP10NL map was used to calculate the percentage of surface water.

The building envelope index, the building volume, the sky-view factor, and shade were based on a 3D model based on the Dutch Elevation Dataset 2 (AHN-2). We considered building volume as an indicator of the capacity to store heat, while we hypothesized that the building envelope index (the total surface of roofs and facades per hectare) might explain the heat exchange between buildings and their surroundings. We calculated the sky-view factor using the SVF Computation Code, which was developed by the Research Centre of the Slovenian Academy of Sciences and Arts (Zakšek et al., 2011).

These actions resulted in maps concerning the impervious surface, surface water, surface albedo, vegetation (NDVI and LAI), shade, sky-view factor, building volume, and building envelope. All maps were again included in the ArcGIS database and expressed in ratios, percentages, and numeric values per hectare.

\subsection{Multivariate regression analysis and cluster analysis}

Daniele Vettorato (2010) pioneered the evaluation of the link between morphology / land use and the land surface temperature, using remote sensing, multivariate regression analysis, and GIS. His case study of the city of Trento, Italy, provided the initial research design for the Hotterdam research project.

We determined links between heat (surface energy balance, temperatures) and the social-spatial dimensions through multivariate regression analysis and hierarchical regression analysis. The first step was to analyse which temperatures / surface energy balance indicator best explained the excess mortality among seniors seventy-five years and older in Rotterdam in July 2006. The second step was to link the indicator that we would find to the morphological / land-use dimensions of the city. We clustered the social and morphological / land-use dimensions that were statistically significant and incorporated these in the social and spatial heat maps. Those heat maps and the underlying data help to understand the vulnerability 
Table 1: Summer 2006 and average summer (2000 - 2013) in Rotterdam, average maximum temperature, and number of deaths among those seventy-five and over.

\begin{tabular}{lllllll}
\hline & \multicolumn{2}{c}{ June } & & July & \multicolumn{2}{c}{ August } \\
\hline Year & $\begin{array}{l}\text { Average max. } \\
\text { temperature }\end{array}$ & $\begin{array}{l}\text { Deaths of } \\
\text { people } 75+\end{array}$ & $\begin{array}{l}\text { Average max. } \\
\text { temperature }\end{array}$ & $\begin{array}{l}\text { Deaths of } \\
\text { people } 75+\end{array}$ & $\begin{array}{l}\text { Average max. } \\
\text { temperature }\end{array}$ & $\begin{array}{l}\text { Deaths of } \\
\text { people } 75+\end{array}$ \\
\hline 2006 & $21.3^{\circ} \mathrm{C}$ & 308 & $27.8^{\circ} \mathrm{C}$ & 385 & $20.5^{\circ} \mathrm{C}$ & 293 \\
\hline $\begin{array}{l}\text { Average } \\
2000-2013\end{array}$ & $20.7^{\circ} \mathrm{C}$ & 298 & $22.4^{\circ} \mathrm{C}$ & 310 & $22.3^{\circ} \mathrm{C}$ & 292 \\
\hline
\end{tabular}

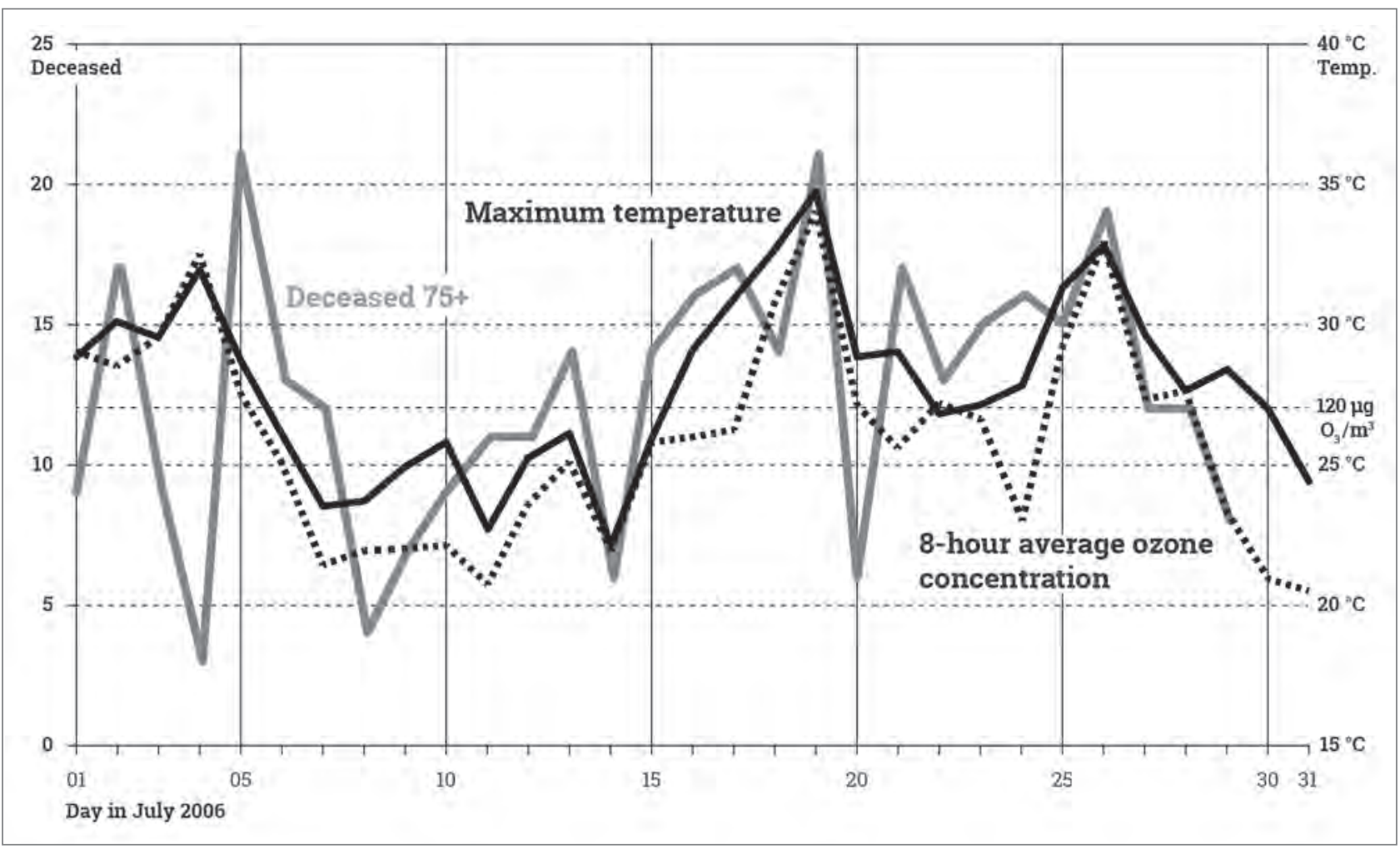

Figure 3: The 2006 heat wave in Rotterdam, deaths of seniors seventy-five and over, maximum daytime temperature (in ${ }^{\circ} \mathrm{C}$ ) and ozone (source: van der Hoeven \& Wandl, 2015c).

of Rotterdam's senior citizens to the urban heat island effect during heatwaves.

We first used hierarchical multiple regression analysis for all hectares in the research area to establish which of the aspects improve the prediction of all the deceased inhabitants seventy-five and over. We added to the model outdoor and indoor temperature, surface temperature, net radiation, sensible heat, latent heat, storage heat flux, energy labels, and building ages. Next, we ran a multiple regression analysis to predict the urban heat island based on the spatial / morphological dimensions of the city of Rotterdam. Here we added to the model impervious surface, surface water, surface albedo, vegetation (NDVI and LAI), shade, sky-view factor, building volume, and building envelope. The assumptions of linearity, independence of errors, homoscedasticity, unusual points, and normality of residuals were met. Finally, we used two-step cluster analyses based on the results of the regression analyses for all inhabited grid cells across the city. The analyses led to distinct clusters (or typologies) that became the basis for the social and a spatial heat maps.

\section{Results}

\subsection{What a future Rotterdam summer may look like: July 2006}

Based on KNMI and CBS data, we found that July 2006 was the summer month with the highest average maximum temperature in Rotterdam $\left(27.8^{\circ} \mathrm{C}\right)$ and the highest mortality rate among citizens seventy-five and over, compared to the months of June, July, and August from 2000 to 2013. July 2006 became the hottest month in three hundred years of recorded Dutch weather history. The CBS (2006) reported that one thousand 


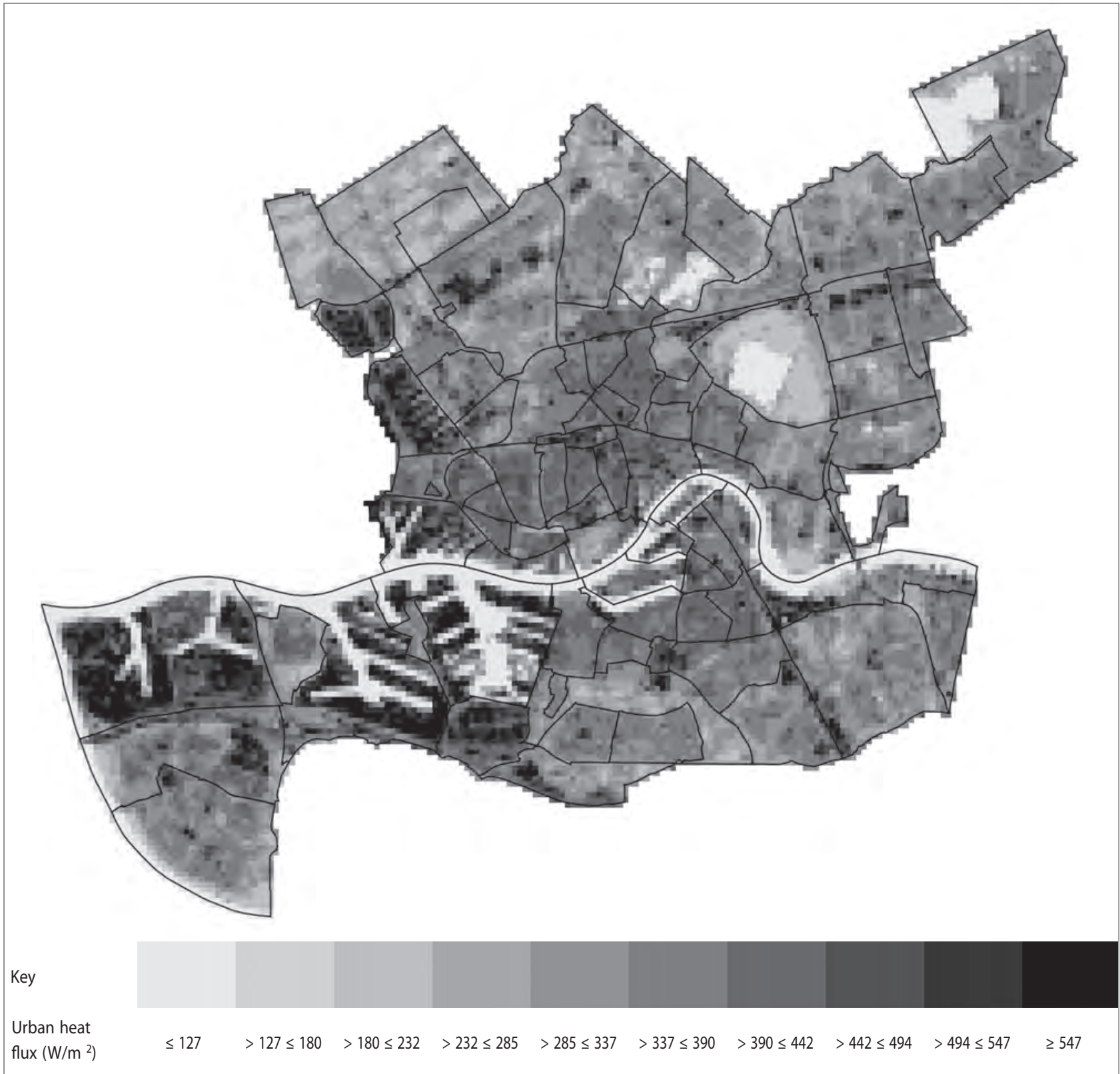

Figure 4: The sum of the sensible and storage heat fluxes, 16 July 2006 (author: Frank van der Hoeven).

more Dutch citizens than average died during July 2006. With one thousand deaths as the result of the record heat, the Netherlands was placed third in the world's meteorological disaster rankings in 2006 (CRED, 2016). Reviewing these facts made us decide to work with July 2006 as a model for future Rotterdam summers. The city of Rotterdam registered seventy-five more deaths among seniors in July 2006 than in an average July (as compared to 2000 to 2013). Compared to the mean over the period 2007 - 2013, this figure would even be as high as ninety additional deaths.

The overview of the day-by-day data for July 2006 shows that the peak in mortality rates among senior citizens in Rotterdam occurred two to three days after the peak in temperature, similar to the observation of the CBS back in 2006. The concentrations of ozone peaked on the same days as the outdoor temperature. The data at this point, however, are not sufficiently precise to correlate with the increased mortality. Ozone is only measured at three locations in the city of Rotterdam. However, there is a real possibility that the health impact of the 2006 heat wave was (in part) caused through the increased concentration of ozone.

The black line shows the maximum daytime temperature. The dashed line shows the concentrations of ozone. On the right is the European target value of $120 \mu \mathrm{g}$ per cubic metre of air. The grey line shows the mortality rate among those seventy-five and over. The figures for the mortality rate have been shifted 


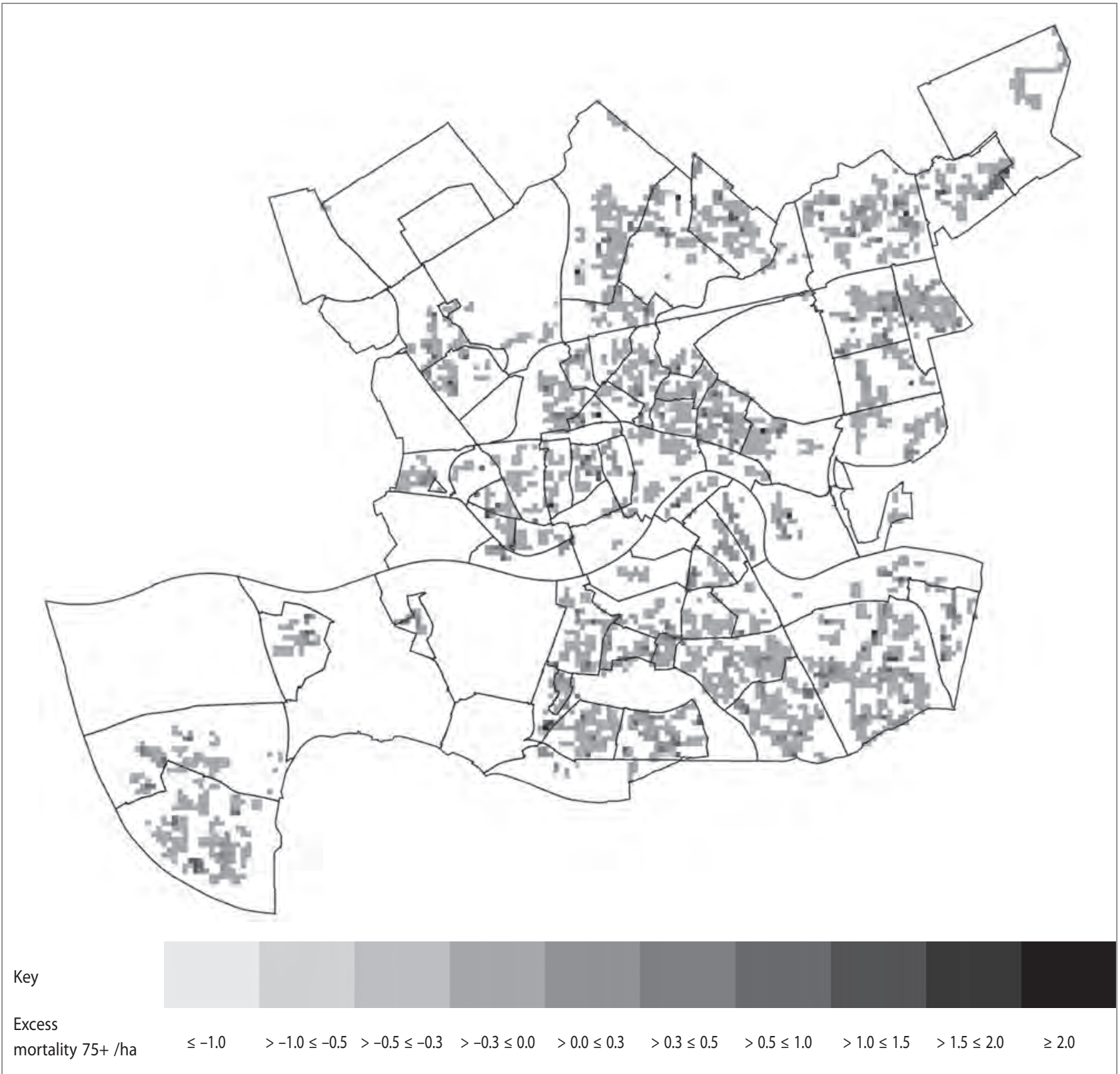

Figure 5: Excess mortality seventy-five and over, July 2006 in absolute numbers (author: Frank van der Hoeven).

backwards by two days, given the time lag. This shift brings together the peaks in temperature, mortality, and ozone

\subsection{Atlas}

The second step in the research design was the processing and mapping of the city of Rotterdam's heat, social characteristics, and morphological / land-use dimensions. This resulted in an ArcGIS database published as an atlas (see van der Hoeven \& Wandl, 2015c). We show two maps in closer detail: the sum of the sensible and storage heat fluxes (Figure 4) and excess mortality among those seventy-five and over (Figure 5). The most prominent case where climate aspects were mapped to visualize and understand its consequences for urban and spatial planning was the Klimafibel 'Climate Booklet' (Ministerium für Verkehr und Infrastruktur Baden-Württemberg, 2004), which we took as an example.

\subsubsection{Heat indicators}

We explored the Rotterdam urban heat island by mapping four potential indicators: the outside and inside air temperature (crowd sensing), the land surface temperature (remote sensing), and the surface energy balance (ATCOR2 analyses based on remote sensing). The data on the surface energy balance, the surface temperature, and the air temperature all point to an apparent heat island effect in Rotterdam. The surface heat island is strongest in the port, industry, and business areas. The 


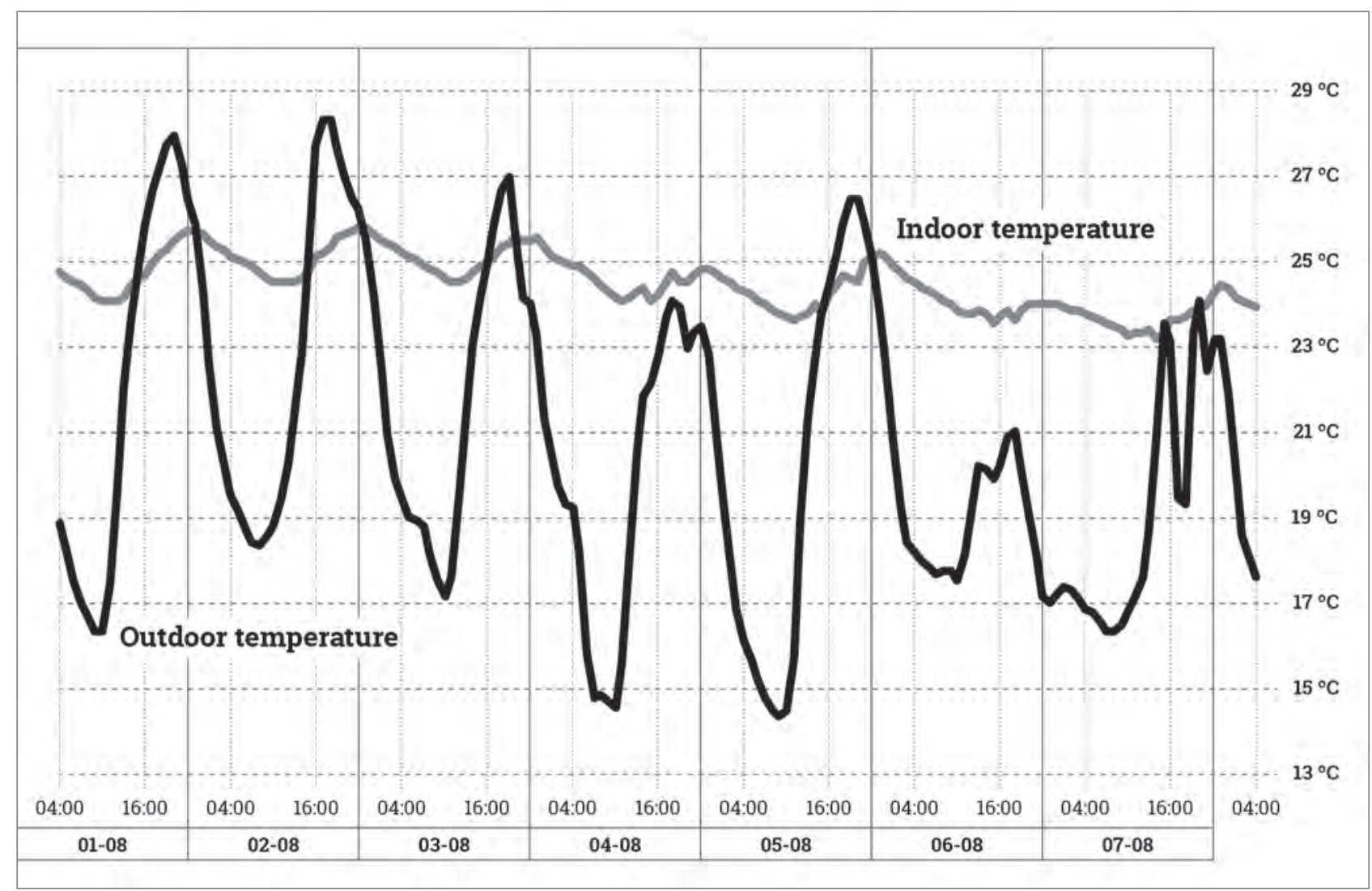

Figure 6: Air temperature measured in selected homes and streets in Rotterdam. The diagrams show the averages of all eight hundred indoor (grey line) and two hundred outdoor temperature (black line) readings in the first week of August 2014 (source: van der Hoeven \& Wandl, 2015c).

city centre and the older, densely built-up residential districts in northern, southern, and western Rotterdam are exposed to a significant atmospheric urban heat island effect.

The results from the crowdsensing measurements were mixed. We encountered sufficient willingness to participate in the study and did not experience difficulty in finding one thousand participants. However, by the time all of the sensors were distributed it was late July, and August 2014 would turn out to be the coldest August in ninety years. The data we collected do provide leads for further research, but they do not represent the heatwave event we hoped for. They did not even resemble an average Dutch summer.

We displayed the averages of measurements of all sensors taken during the first week of August (temperatures above $25^{\circ} \mathrm{C}$ ) in Figure 6. The air temperatures inside homes are on average higher than those taken in the corresponding streets, except for the daily afternoon peaks of the outdoor air temperature. The indoor fluctuations are modest compared to the outdoor temperature differences during the day. The outdoor environment seems to provide a sufficient cooling effect so as to reduce the indoor temperatures during most of the day. Comparing the measurements at an urban scale reveals that the indoor temperatures show less spatial coherence than the outdoor temperatures. The results of our heat analysis are maps that visualize air temperatures (outdoor and indoor), surface temperatures during the daytime, net radiation, latent heat flux, sensible heat flux, and storage heat flux.

\subsubsection{Socio-spatial dimension}

Processing and mapping the social dimensions of urban heat resulted in five maps relating to July 2006:

- The spatial distribution of seniors seventy-five and over;

- The mortality rate of seniors seventy-five and over;

- The above-average mortality rate;

- The age of the buildings; and

- The average building energy labels per hectare.

The vulnerable group of citizens seventy-five and over is strongly concentrated in the post -Second World War districts: Schiebroek, Ommoord, IJsselmonde, Zuidwijk, Pendrecht, and Hoogvliet. Here many old people's homes and care homes are located. The above-average mortality rate during the July 2006 heat wave shows a pattern that is more spread out (Figure 5). We need more indicators to explain the mortality of seniors than merely the spatial concentration of those seventy-five and over. 
Table 2: Full details on each regression model.

\begin{tabular}{|c|c|c|c|c|c|c|}
\hline \multirow{3}{*}{ Variable } & \multicolumn{6}{|c|}{ No. of deceased $75+$} \\
\hline & \multicolumn{2}{|l|}{ Model 1} & \multicolumn{2}{|l|}{ Model 2} & \multicolumn{2}{|l|}{ Model 3} \\
\hline & $B$ & $\beta$ & $B$ & $\beta$ & $B$ & $\beta$ \\
\hline Constant & $0.048^{* *}$ & & $-0.043^{* *}$ & & $-0.58^{* *}$ & \\
\hline No. of $75+(2006)$ & $0.002^{* *}$ & 0.095 & $0.002^{* *}$ & 0.775 & $0.001 * *$ & 0.652 \\
\hline Building age & & & $0.000066^{* *}$ & 0.213 & $0.000034^{* *}$ & 0.108 \\
\hline Urban heat flux (2006) & & & & & $0.000011^{* * *}$ & 0.232 \\
\hline$R^{2}$ & 0.819 & & 0.847 & & 0.859 & \\
\hline$F$ & 320.6 & & 193.6 & & 140.2 & \\
\hline$\Delta R^{2}$ & 0.816 & & 0.843 & & 0.853 & \\
\hline$\Delta F$ & 320.6 & & 12 & & 5.9 & \\
\hline
\end{tabular}

** $p<.005$

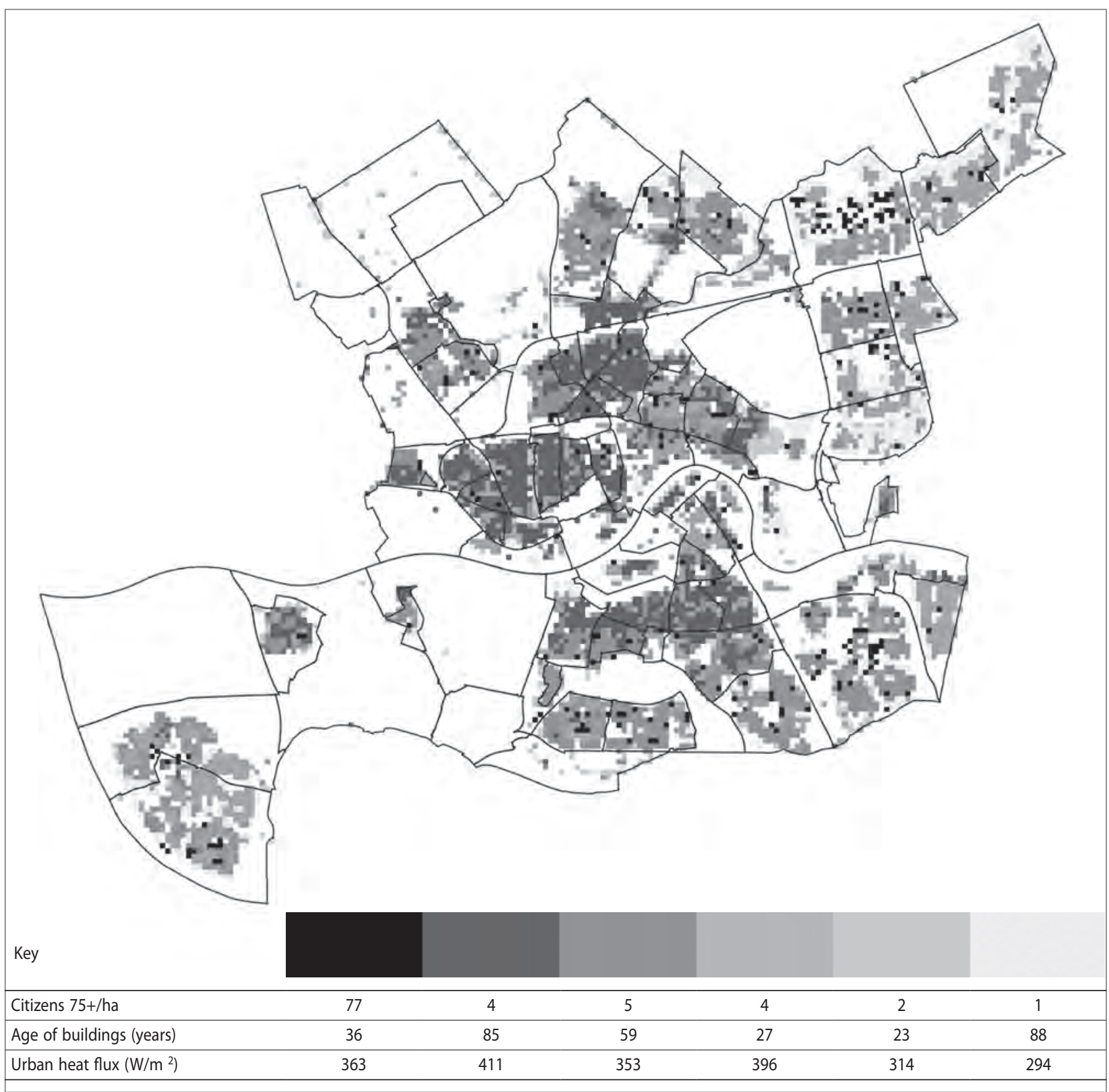

Figure 7: Social heat map: the spatial pattern of the vulnerability of the elderly to the urban heat island effect in the city of Rotterdam (source: van der Hoeven \& Wandl, 2015c). 
Table 3: Regression coefficients and standard errors.

\begin{tabular}{llll}
\hline Variable & $\mathrm{B}$ & $S E_{B}$ & $\beta$ \\
\hline Constant & 281.3 & 2.6 & $-0.313^{* *}$ \\
\hline Water & -0.011 & 0.0002 & $0.680^{* *}$ \\
\hline Imperviousness & 217.8 & 2.708 & $-0.077^{* *}$ \\
\hline Leaf area index & -0.13 & 0.001 & $-0.005^{* *}$ \\
\hline Building envelope & -0.0002 & 0.0001 & $-0.086^{* *}$ \\
\hline Shade & $-1.034 \mathrm{E}-06$ & $4.2475 \mathrm{E}-08$ & 5 \\
\hline
\end{tabular}

Note: ${ }^{* *} p<.005 B=$ unstandardized regression coefficient, $S E_{B}=$ standard error of the coefficient; $\beta=$ standardized coefficient. Dependent variable: urban heat flux.

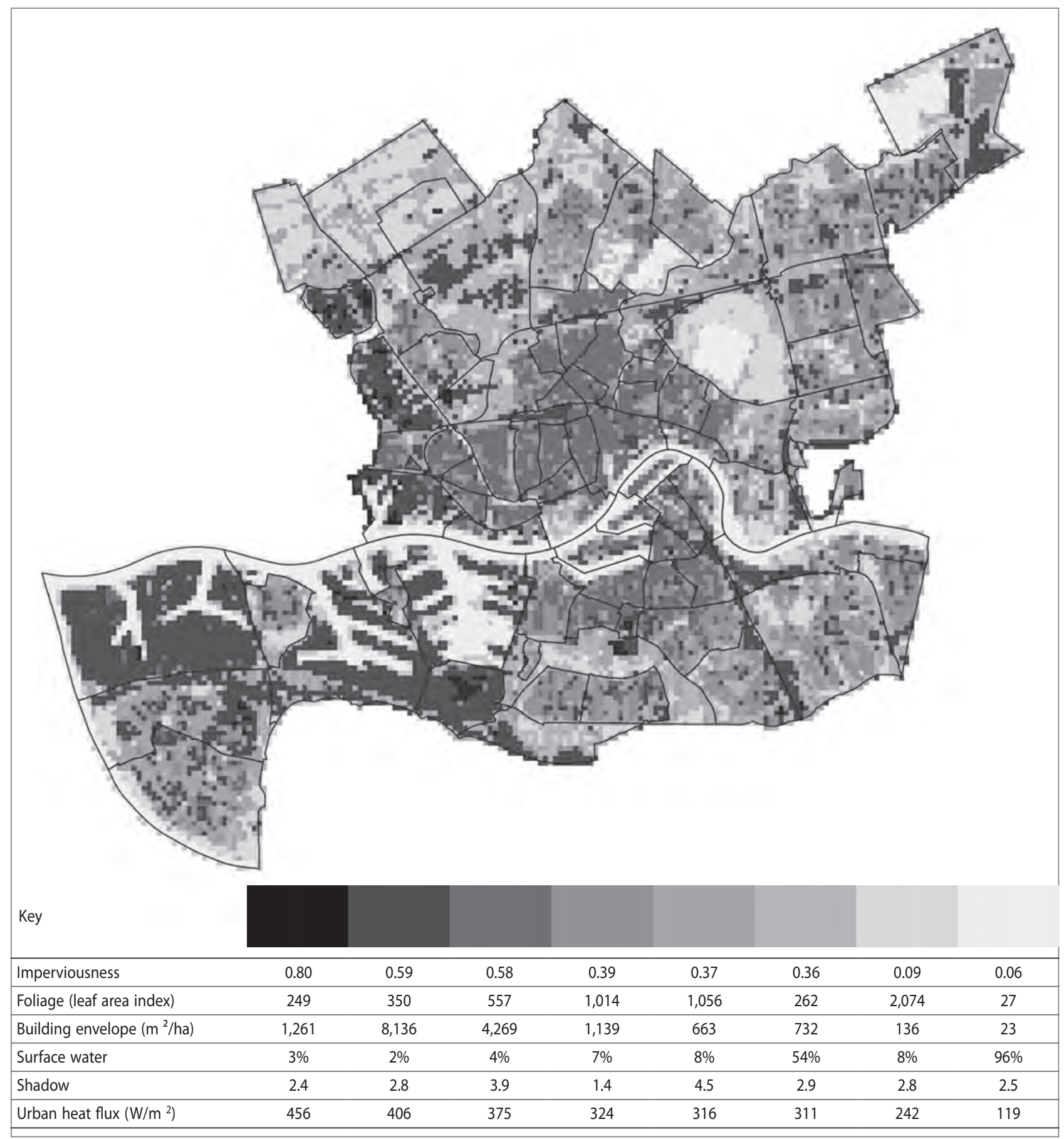

Figure 8: Spatial heat map: the spatial pattern of land use and urban form that contributes in a greater or lesser degree to the urban heat island in the city of Rotterdam (source: van der Hoeven \& Wandl, 2015c). 
A multivariate regression analysis was used to explore where in Rotterdam vulnerability to heat leads to problems for seniors. In July 2006, 385 elderly citizens died, whereas we can only consider seventy-five to ninety deaths as excess mortality. We used hierarchical multiple regression analysis for all hectares to establish which of the social aspects would improve the prediction of the number of deceased inhabitants that were seventy-five or older. Added to the model were outdoor and indoor air temperature, surface temperature, net radiation, sensible heat flux, latent heat flux, storage heat flux, energy labels, and building age.

The full model using the number of inhabitants seventy-five and over, the sum of sensible heat and storage heat flux, and the mean building age was statistically the most significant in predicting the number of deceased citizens seventy-five and over. The addition of the sum of sensible heat flux and storage heat flux to predict the number of deceased inhabitants seventy-five and over led to a statistically significant increase in $R^{2}$ of $0.050, F(2,71)=4.2147, p<0.05$. The addition of building age to the prediction of deceased $75+($ Model 3 ) also led to a statistically significant increase in $R^{2}$ of 0.093 , $F(1,95)=8.699, p<0.005$. See Table 2 for full details on each regression model for the number of deceased inhabitants seventy-five years and over.

A two-step cluster analysis for all inhabited grid cells across the city used the outcome of the regression analysis: the number of inhabitants seventy-five or over, the mean age of buildings, and the sum of sensible heat and storage heat flux. That cluster analysis resulted in six clusters (or typologies) that are shown here on the map (Figure 8), together with a table explaining the underlying values. The distribution of seniors in Rotterdam still reflects the custom of the Dutch to concentrate their seniors in care institutions (located in black hectares on the map). These spatial pockets require special attention. The neighbourhoods around the centre of Rotterdam (north, south, and west) need a policy response as well. These districts may have fewer seniors per hectare, but they experience higher levels of urban heat. The homes here are relatively old, and these areas are quite extensive.

\subsubsection{Spatial dimension}

The sum of sensible heat flux (heat that warms up air) and storage heat flux (heat that warms up buildings) was the best indicator explaining the urban heat island effect on the vulnerable part of the Rotterdam population. In a further step we explored which morphological elements or land uses account for the sum of sensible heat flux and storage heat flux.
For this clustering we used maps of impervious surfaces, surface water, albedo, vegetation, shade, sky view, building volume, and building envelope. This clustering provides insights into which combinations of morphology and land use the city should avoid and which it should apply more frequently.

A multiple regression analysis was run to predict the sum of sensible heat and storage heat flux. The variables imperviousness, leaf area index, building envelope index, surface water, and shade performed best in predicting the urban heat island effect, $F(5,15,951)=19,167.694, p<.0005$, adj. $R^{2}=.857$. All five variables added statistically significantly to the prediction, $p<.0005$. Table 3 shows regression coefficients and standard errors.

A two-step cluster analysis for all grid cells $(100 \mathrm{~m} \times 100 \mathrm{~m})$ across the city used the outcome of the regression analysis: imperviousness, leaf area index, building envelope index, surface water, and shade. The clustering resulted in eight combinations of morphology and land use features. These are shown on the map in Figure 8, just above the table that explains the underlying values. The port, industry, and business areas play an important role in the formation of the urban heat island in Rotterdam. These areas did not appear on the social heat map because no (senior) citizens live there. The Rotterdam city centre and the surrounding densely built-up districts (north, south, and west) possess more morphological and land-use features that are at the root of the urban heat island problem than other parts of the city.

\section{Conclusion}

The Hotterdam project examined the urban heat island effect in Rotterdam by answering four research questions:

1. Does the urban heat island effect impact all parts of the city of Rotterdam equally, or are distinct districts more affected than others, and which areas are these?

The urban heat island effect does not impact all parts of Rotterdam equally. The industrial and harbour areas in Rotterdam experience the urban heat island effect most strongly. The districts north, south, and west of the Rotterdam city centre are more strongly affected than the rest of the city.

2. Does a link exist between the urban heat island in the city of Rotterdam and the mortality rate among senior citizens during heatwaves?

We established reasons for the above-average mortality among elderly citizens and explained the spike in the above-average mortality of seniors seventy-five and over in July 2006 in Rotterdam statistically based on: 
- The spatial distribution of people in this age group;

- The year that their homes were built; and

- The sum of sensible heat flux and storage heat flux.

3. Can the differences in the urban heat island effect between districts be explained by the morphology and land use of the city of Rotterdam?

Yes. A district experiences differences in the accumulation of urban heat (and the associated public health problems) due to a combination of morphology and land use:

- Impervious surfaces;

- Surface water;

- Foliage (green);

- Building envelopes; and

- Shade.

These dimensions primarily determine whether a district faces more or rather less accumulation of urban heat and associated public health problems.

4. Do the social, morphological, and land-use dimensions of the urban heat island effect represent coherent spatial patterns that allow an area-oriented approach in the urban planning and management of the city?

The cluster analyses of the data did produce coherent spatial patterns. The industrial and harbour areas in Rotterdam are strongly associated with the urban heat island. Because no one lives in these areas, we advise that policies focus on the pre-Second World War districts instead: the districts directly north, south, and west of the Rotterdam city centre. These districts are affected by a relatively high land surface temperature, a relatively high sum of sensible heat and storage heat flux, and higher outdoor temperatures. In addition, the percentage of the elderly living in these areas is still significant.

\section{Frank van der Hoeven}

TU Delft, Faculty of Architecture and the Built Environment, Delft,

Netherlands

E-mail: f.d.vanderhoeven@tudelft.nl

\section{Alexander Wandl}

TU Delft, Faculty of Architecture and the Built Environment, Delft, Netherlands

E-mail: a.wandl@tudelft.nl

\section{Acknowledgments}

The Hotterdam research project was carried out in the context of Climate Proof Cities, a consortium in the Dutch research programme "Knowledge for Climate" (Albers et al., 2015). The Hotterdam research project expresses its gratitude for being able to use the results of one of the 4TU.Bouw Lighthouse Projects, which was made possible by the 4TU.Federation: Sensing Hotterdam. Sensing Hotterdam was a joint project by Delft University of Technology and Eindhoven University of Technology.
The initial findings of the Hotterdam study were captured in an open access publication written in Dutch with a broad, but local, audience in mind (van der Hoeven \& Wandl, 2015b), also available in English (van der Hoeven \& Wandl, 2015c). To allow closer inspection of the results, we stored the entire dataset in the open data repository of the 4TU.Centre for Research Data (Wandl \& van der Hoeven, 2015).

\section{References}

Albers, R. A. W., Bosch, P. R., Blocken, B., van den Dobbelsteen, A. A. J. F., Van Hove, L. W. A., Spit, T. J. M., et al. (2015) Overview of challenges and achievements in the Climate Adaptation of Cities and in the Climate Proof Cities program. Building and Environment, 83, pp. 1-10. DOI: 10.1016/j.buildenv.2014.09.006

Barsi, J. A., Schott, J. R., Palluconi, F. D. \& Hook, S. J. (2005) Validation of a web-based atmospheric correction tool for single thermal band instruments. In: Butler, J. J. (ed.) Proceedings of SPIE, Earth Observing Systems $X, 58820$ E, pp. 1-7. Bellingham, WA, SPIE. DOI: 10.1117/12.619990

CBS (2006) July heat causes one thousand extra deaths. Available at: https://www.cbs.nl/en-gb/news/2006/35/july-heat-causes-one-thousand-extra-deaths (accessed 16 Feb. 2018).

CBS \& PBL (2011) Forse bevolkingsgroei in de Randstad tot 2025. Available at: http://www.cbs.nl/NR/rdonlyres/FE3DD1BE-D1FF-46C6-BB49092F4B2E4DEC/0/pb11n064.pdf (accessed 14 Feb. 2018).

Chapman, L., Bell, C. \& Bell, S. (2017) Can the crowdsourcing data paradigm take atmospheric science to a new level? A case study of the urban heat island of London quantified using Netatmo weather stations. International Journal of Climatology, 37(9), pp. 3597-3605. DOI: 10.1002/joc.4940

CRED (2016) EM-DAT: The International Disaster Database. Available at: http://www.emdat.be/disaster_list/index.html (accessed 14 Feb. 2018).

de Jong, A. \& Daalhuizen, F. (2014) De Nederlandse bevolking in beeld: verleden heden toekomst. The Hague, Planbureau voor de Leefomgeving.

Dousset, B. \& Gourmelon, F. (2003) Surface temperatures of the Paris Basin during summertime, using satellite remote sensing data. In: Klysik, K. (ed.) Proceedings of the 5th International Conference on Urban Climate, Łódź, Poland, University of Łódź. Available at: https://pdfs. semanticscholar.org/a11e/9ac6e77d27b0f2e0212d8f40b656149cce54. pdf (accessed 16 Feb. 2018).

Dousset, B., Gourmelon, F., Laaidi, K., Zeghnoun, A., Giraudet, E., Bretin, P., et al. (2011) Satellite monitoring of summer heat waves in the Paris metropolitan area. International Journal of Climatology, 31(2), pp. 313323. DOI: $10.1002 /$ joc.2222

Harman, I. N. (2003) The energy balance of urban areas. Doctoral thesis. Reading, UK, The University of Reading. Available at: http://www.met. rdg.ac.uk/phdtheses/The\%20energy\%20balance\%20of20urban\%20areas.pdf (accessed 14 Feb. 2018).

Heaviside, C., Vardoulakis, S. \& Cai, X. M. (2016) Attribution of mortality to the urban heat island during heatwaves in the West Midlands, UK. Environmental Health, 15(1), pp. 49-59. DOI: 10.1186/s12940-016-0100-9

KNMI (2014) KNMI'14 klimaatscenario's voor Nederland. De Bilt, Netherlands.

Mavrogianni, A., Davies, M., Batty, M., Belcher, S. E., Bohnenstengel, S. I., Carruthers, D., et al. (2011) The comfort, energy and health implications of London's urban heat island. Building Services Engineering Research and Technology, 32(1), pp. 35-52. DOI: 10.1177/0143624410394530 
Ministerium für Verkehr und Infrastruktur Baden-Württemberg (2004) Städtebauliche Klimafibel: Hinweise für die Bauleitplanung, Folge, 1. Stuttgart.

Rydin, Y., Bleahu, A., Davies, M., Dávila, J. D., Friel, S., De Grandis, G., et al. (2012) Shaping cities for health: complexity and the planning of urban environments in the 21st century. Lancet, 379(9831), pp. 20792108. DOI: $10.1016 / 50140-6736(12) 60435-8$

Vandentorren, S., Bretin, P., Zeghnoun, A., Mandereau-Bruno, L., Croisier, A., Cochet, C., et al. (2006) August 2003 heat wave in France: Risk factors for death of elderly people living at home. European Journal of Public Health, 16(6), pp. 583-591. DOI: 10.1093/eurpub/ckl063

van der Hoeven, F. \& Wandl, A. (2015a) Amsterwarm: Mapping the landuse, health and energy-efficiency implications of the Amsterdam urban heat island. Building Services Engineering Research and Technology, 36(1), pp. 67-88. DOI: 10.1177/0143624414541451

van der Hoeven, F. D. \& Wandl, A. (2015b) Hotterdam. Hoe ruimte Rotterdam warmer maakt, hoe dat van invloed is op de gezondheid van inwoners, en wat er aan te doen is. Delft, TU Delft.

DOI: 10.7480/bkbooks/hotterdam/nl

van der Hoeven, F. D. \& Wandl, A. (2015c) Hotterdam: How space is making Rotterdam warmer, how this affects the health of its inhabitants, and what can be done about it. Delft, TU Delft. DOI: 10.7480/bkbooks/hotterdam/en

van der Hoeven, F., Wandl, A., Demir, B., Dikmans, S., Hagoort, J., Moretto, M., et al. (2014) Sensing Hotterdam: Crowd sensing the Rotterdam urban heat island. SPOOL, 1(2), pp. 43-58.

DOI: $10.7480 /$ spool.2014.2.935

van Duin, C. \& Stoeldraijer, L. (2014) Bevolkingsprognose 2014-2060: groei door migratie. The Hague, BS.

Vettorato, D. (2010) Urban planning and design for local climate mitigation. A methodology based on remote sensing and GIS. Paper presented at the 46th ISOCARP Congress 2010, Nairobi, Kenya. Available at: http:// www.isocarp.net/Data/case_studies/1815.pdf (accessed 14 Feb. 2018).

Wandl, A. \& van der Hoeven, F. (2015) Hotterdam: Urban heat in Rotterdam and health effect. Dataset. Delft, TU Delft. Available at: http:// dx.doi.org/10.4121/uuid:be41b523-1f1a-4f46-82d1-09c2c24f357b (accessed 14 Feb. 2018). DOI: 10.7480/spool.2014.2.935

Yale Center for Earth Observation (2010) Converting Landsat TM and ETM+ thermal bands to temperature. Available at: http://citeseerx.ist.psu. edu/viewdoc/summary?doi=10.1.1.187.6113 (accessed 16 Feb. 2018).

Zakšek, K., Oštir, K. \& Kokalj, Ž. (2011) Sky-view factor as a relief visualization technique. Remote Sensing, 3(2), pp. 398-415.

DOI: $10.3390 /$ rs3020398 